\title{
Physiological Effects of Five Herbicides on Wheat Cultivars
}

\author{
Veli Çeliktaş, Sema Düzenli, Hande Otu \\ Cukurova University \\ Faculty of Science and Literature, Biology Departmant, Sarıçam Adana, Turkey \\ vceliktas@cu.edu.tr; sduzenli@cu.edu.tr; hotu@cu.edu.tr
}

\section{Extended Abstract}

Herbicides are chemical compounds which used for struggle with weeds to protect the crops in fields. However, it can be harmful to crops sometimes. The aim of this study, to investigate the effects of herbicides on crops. For this purpose five different herbicides applied to wheat cultivars ( Triticum aestivum cvs Adana 99 and Ceyhan 99; Triticum drum cv Selçuklu 97).

Seed samples were sterilized in a $\% 3$ sodium hypochlorite solution for three minutes and washed several times with distilled water.Then seeds were sown in plastic pots which had 1000 gr soil and 40 seeds per pots.Pots were placed at 24/20 C (day/night) temperature and 16/8 light period (day/night), with a light intesity of $300 \mu \mathrm{mol} / \mathrm{m}^{2} \mathrm{~s}$, and $\% 60$ humidity in a controlled room. Herbicides $(2,4 \mathrm{D}$, Derby, Atlantis, Topic, Lintur) were sprayed with a spray gun ( 5000 $\mathrm{L} /$ ha volume $)$ in a controlled room $\left(15^{\circ} \mathrm{C}\right)$ two weeks after germination. Plants were harvested when beginning of tillering three weeks after herbicide application.

Pigment, proline (an aminoacide that increase against stress), lipid peroxidation (LP, which degrades membrane integrity), ascorbic acid ( a non-enzymatic antioxidant) and SOD (superoxide dismutase, a antioxidative enzyme that remove reactive oxygen species) analisies were conducted respectively according to Arnon 1949 and Lichtenthaler and Wellburn, 1983; Bates et al. (1973); Hodges et al.,1998; Cakmak and Marshner, 1992.

Statistical analysis of data of the application was performed using the software SPSS ${ }^{\circledR}$ Statistics 20.0 (IBM Corporation, New York, NY, USA). Each parameter was analyzed seperately by one-way analysis of variance (ANOVA) to evaluate the changes in each application. Significant differences $(p<0,05)$ reanalyzed by LSD (Least Significant Difference) to determine which parameter was significantly different from controls.

Derby, Topic and Lintur herbicides affected the ascorbic acid content of Adana 99 cultivar negatively. But only Lintur effected ascorbic acid content significiantly according to LSD ( $p<0,05)$. It was observed significantly that Topic has negative effect on total chlorophyll, malondialdehyde (MDA; biomarker to measure the level of LP), superoxide dismutase activity and carotenoid content, unlike Topic 2,4D had pozitive effect on carotenoid content . The herbicides exclusive Derby increased prolin content significantly of this cultivar. It was determined that Topic had been the most toxic herbicide for Adana 99 cultivar.

In Ceyhan 99 cultivar; Topic and Atlantis affected positively ascorbic acid level $(\mathrm{p}<0,05)$. Atlantis decreased carotenoid level and in addition to this increased ascorbic acid content. Topic had riser effect on ascorbic acid and proline concentration. The herbicides had no significant effect MDA and total chlorophyll content. Derby and 2,4D had negative affect on SOD activity.

In Selçuklu 97 cultivar Topic had negative effect on ascorbic acid level ( $\mathrm{p}<0,05)$. All of the herbicides exclusive 2,4D had significant increasing effect on total chlorophyll content. Atlantis and Lintur increased carotenoid level. Derby and Atlantis increased MDA content while whole herbicides decreased SOD activity. Proline was not affected by herbicide applications significantly.

\section{References}

[1] D. I. Arnon, "Copper Enzymes in Isolated Chloroplasts Polyphenoloxidase in Beta Vulgaris," Plant Physiology, vol. 24, pp. 1-15, 1949.

[2] H. K. Lichtenthaler and A. R. Welburn, "Determinations of Total Carotenoids and Chlorophylls A and B of Leaf Extracts in Different Solvents," 603 ${ }^{\text {rd }}$ Meeting Held at the University Of Liverpool, vol. 11, pp. 591, 1983. 
[3] L. S. Bates, R. P. Waldern, and I. D. Teare, "Rapid Determination of Free Prolin For Water-Stress Studies," Plant and Soil, vol. 39, pp. 205-207, 1973.

[4] D. M. Hodges, J. M. Delong, C. F. Forney, and R. K. Prange, "Improving the Thiobarbituric Acid Reactive Substances Assay For Estimating Lipid Peroxidation In Plant Tissues Containing Anthocyanin And Other Interfering Compounds," Planta, vol. 207, pp. 604-611, 1999.

[5] I. Çakmak and H. Marschner, "Magnesium Deficiency and High Light Intensity Enhance Activities of Superoxide Dismutaz, Ascorbate Proxidase and Glutation Reduktase in Bean Leaves," Plant Physiology, vol. 98, pp. 1222-1227, 1992. 